\title{
NMR Studies of Complexes of Fluorides of Triethylamine
}

\author{
N. Ilayaraja ${ }^{1}$, S. Radha Krishnan ${ }^{1, *}$, G. Ravindran ${ }^{2}$ and N. G. Renganathan ${ }^{2}$ \\ ${ }^{1}$ CSIR-Central Electrochemical Research Insititute, Karaikudi, 630 006, India \\ ${ }^{2}$ Vel Tech Dr.RR \& Dr.SR.University, Avadi, Chennai, 600 062, India
}

\begin{abstract}
Different mole ratio of triethylamine $\mathrm{HF}\left(\mathrm{Et}_{3} \cdot \mathrm{nHF}, \mathrm{n}=3,4\right.$ and 5) adducts were prepared and ${ }^{1} \mathrm{H}$ and ${ }^{19} \mathrm{~F}$ NMR spin-lattice relaxation was measured at various temperatures for these three adducts. From this data the bond length and dipole properties of these three adducts were studied. These three adducts can be readily identified by ${ }^{19} \mathrm{~F}$ NMR chemical shifts.
\end{abstract}

Keywords: Hydrogen fluorides, adducts, NMR, spin-lattice relaxation.

\section{INTRODUCTION}

Fluorine atom in a molecule is going to have significant influence on the biological and physical properties of compounds. The compounds thus synthesized will have increase of membrane permeability, hydrophobic binding and stability against metabolic oxidation and these are due to the presence of fluorine compounds, being bioactive compounds, are expected to play a vital role in medicinal chemistry. In view of high rate of growth in the medicinal field the synthesis of organo fluorine compounds gains importance [1-4]. Despite the availability of multi step chemical routes, attempts have been made in this laboratory to synthesize fluorination of amine through single step electrochemical fluorination. For partial fluorination of aromatic compounds the electrochemical method, in fluoride containing solvent free electrolyte systems, has been extensively studied in this laboratory and reviewed [5-8]. These studies are mainly aimed at to fluorinate active methylene group attached to sulfur atom. In continuation of the electrochemical fluorination work in this laboratory efforts are made to fluorinate nitrogen containing aliphatic compounds and in this series electro-fluorination of triethylamine has been done and the resulting products have been analyzed from the spectroscopic angle, especially using NMR and the results are presented in this paper.

In aprotic solvents or amine complexes, acids $\mathrm{AH}$ and bases $\mathrm{B}$ can form a number of different hydrogen bonded complexes. In aqueous solutions $\mathrm{AH}$ and $\mathrm{B}$ are separated. Hydrogen bonded to water molecules can have only two protonation states [9]. Several complexes of pyridine are formed with number of $\mathrm{HF}$ complexes, like $(\mathrm{AH})_{\mathrm{n}} \mathrm{B}$ [10] with a varying number of HF molecules. In the present study three types of HF adducts with triethylamine complexes as indicated in the Fig. (1) can be considered.

These may be $\left(\mathrm{C}_{2} \mathrm{H}_{5}\right)_{3} \mathrm{~N}$.3HF, $\left(\mathrm{C}_{2} \mathrm{H}_{5}\right)_{3} \mathrm{~N}$.4HF and $\left(\mathrm{C}_{2} \mathrm{H}_{5}\right)_{3}$ N.5HF. In these studies the addition of HF reduces

*Address correspondence to this author at the Central Electrochemical Research Insititute, Karaikudi, 630 006, India; Tel: 04565 - 227550; Fax: 04565 - 227205; E-mail: radha_1965@yahoo.com the F-N distances as we move from triethylamine 5HF adduct to triethylamine to $3 \mathrm{HF}$ adduct [11]. The present study aims to understand the addition of HF molecules to the parent triethylamine electrolyte when electro-fluorination is undertaken.

\section{EXPERIMENTAL}

\section{Chemicals}

High pure (>99\%) triethylamine was purchased from Sisco Research Laboratory, India. Anhydrous hydrogen fluoride (AHF) $>99.9 \%$ was obtained from M/s TANFAC, Cudalore, Tamilnadu, India.

\section{Equipment}

${ }^{1} \mathrm{H}$ NMR spectra were recorded with $400 \mathrm{MHz}$ Bruker NMR Spectrometer with $\mathrm{CDCl}_{3}$ and TMS as solvent and reference, respectively. ${ }^{19} \mathrm{~F}$ NMR $(376.5 \mathrm{MHz})$ of the products was recorded using $\mathrm{CFCl}_{3}$ as internal reference.

\section{Preparation of $\mathrm{Et}_{3} \mathrm{~N} . \mathrm{nHF}$}

$\mathrm{Et}_{3} \mathrm{~N}$.3HF is a well-known conventional electrolyte medium for selective electrochemical fluorination. The following procedure was adopted for the preparation of $\mathrm{Et}_{3} \mathrm{~N}$. $3 \mathrm{HF}$. A long jar of high-density polypropylene was cooled with ice salt mixture in a well-ventilated fume chamber. Slightly excess quantity of ( $>4$ mole) anhydrous hydrogen fluoride (AHF) was taken to account for possible loss due to volatility of AHF. The reaction vessel was provided with magnetic stirrer and closed with a lid containing a provision for inlet and an outlet tube for the release of AHF vapors during the reaction. One mole of pre-cooled triethylamine was added drop wise using separating funnel. After the completion of addition of each drop, sufficient time was given to ensure cooling of the reactant mixture. The overall addition was completed in $3 \mathrm{~h}$. The HF content was determined by acidbase titration. Excsess of AHF if any beyond 1:3 mole ratio of $\mathrm{Et}_{3} \mathrm{~N}$.nHF in the mixture was appropriately compensated by the addition of triethylamine. The same procedure was 
<smiles>CCN(CC)CC</smiles><smiles>[PbH2+]</smiles>

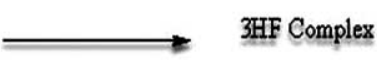<smiles>CCN(CC)CC</smiles>

\section{$(\mathrm{HF})_{3} \mathrm{~F}$}

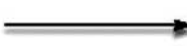

4HF Complex<smiles>CCN(CC)CC</smiles>

\section{$\left(\mathrm{HF}_{4} \mathrm{~F}\right.$}

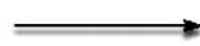

5HF Complex

Fig. (1). Structure of Triethylamine HF adducts.

repeated for the preparation of $\mathrm{Et}_{3} \mathrm{~N}$.4HF and $\mathrm{Et}_{3} \mathrm{~N} .5 \mathrm{HF}$ mixture.

\section{RESULTS AND DISCUSSION}

Fig. (1) shows the structures of the various complexes that are likely to be formed in the present study. Figs. $(2,3$ \& 4) gives the temperature variations of ${ }^{1} \mathrm{H}$ NMR spectra of solutions of triethylamine and HF where the HF ratio to triethylamine is 5,4 , and 3:1. The spectra show major spectral changes arising from the formation of various complexes assigned to structures as depicted in Fig. (1).

The Fig. (2) shows the effect of temperature on the adduct of fluorine complex with triethyl amine. As temperature increases the downfield shift takes place. Normally these chemical shifts take place due to dipole dipole interactions in hydrocarbon and fluorocarbon groups. But in this case when adducts are formed the chemical shift may occur due to relaxation caused by interaction between nucleai and unpaired electron spins.

Fig. (3) shows the adduct of HF with triethylamine with 4HF. As temperature increases the shift takes place towards more positve and as temperature goes down they try to come closer and negative shift occurs. This clearly indicates the formation of $\mathrm{NH}$ bond and deviates from HF bond. Since fluorine being more electronegative compared to nitrogen, which contains lone pair of electrons, is beneficial for the formation of absorbing proton the downfield shift occurs. This is more predominant in the case of $4 \mathrm{HF}$ compared to $3 \mathrm{HF}$ where the shift is of more or less having equal magnitude.

Fig. (4) shows the chemical shift of the adduct 5HF with tri ethyl amine. Here the effect is due to lone pair electrons in the nitrogen. There is a transition at the temperature $0^{0} \mathrm{C}$ where the shift is appreciable. This indicates that there is a preferential formation of $\mathrm{N}-\mathrm{H}$ bond compared to the detachment of hydrogen bond from HF and thus enables the formation of adduct of HF with triethylamine.

Figs. (5, 6 \& 7) imply that as the temperature decreases downfield shift takes place from 173 to $168 \mathrm{ppm}$. This clearly gives an idea of change in the bond distance of $\mathrm{HF}$ as the temperature goes down. In 4HF down filed shift takes place from 183 to $173 \mathrm{ppm}$ as temperature decreases. In 5HF again down field shift takes place from 186 to $176 \mathrm{ppm}$. It is seen that from up field shift as it gets fluorinated in aprotic environments, due to competition with the solvent, weak hydrogen bonding is expected and is generally found. It has

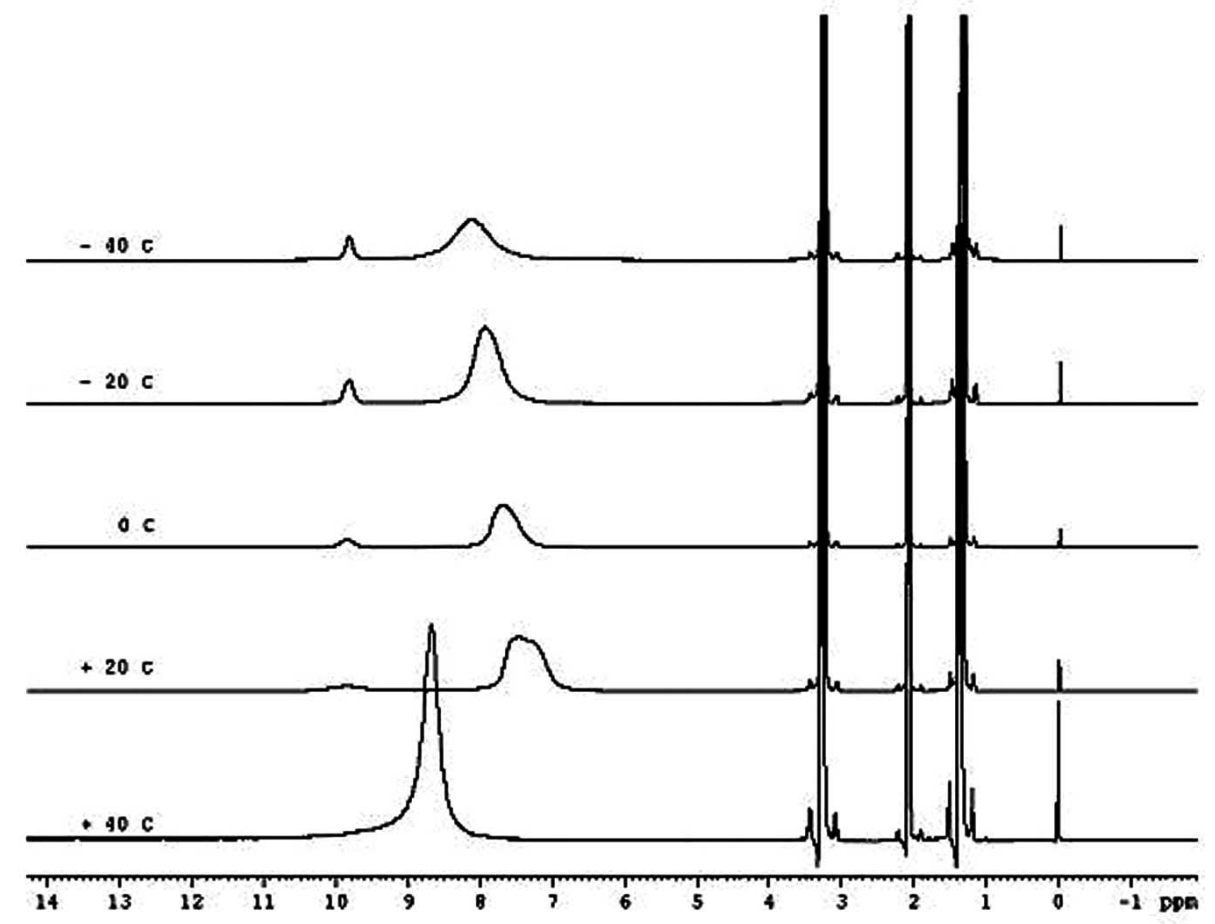

Fig. (2). ${ }^{1} \mathrm{H}$ NMR spectra of triethylamine $3 \mathrm{HF}$ adduct recorded at various temperatures. 


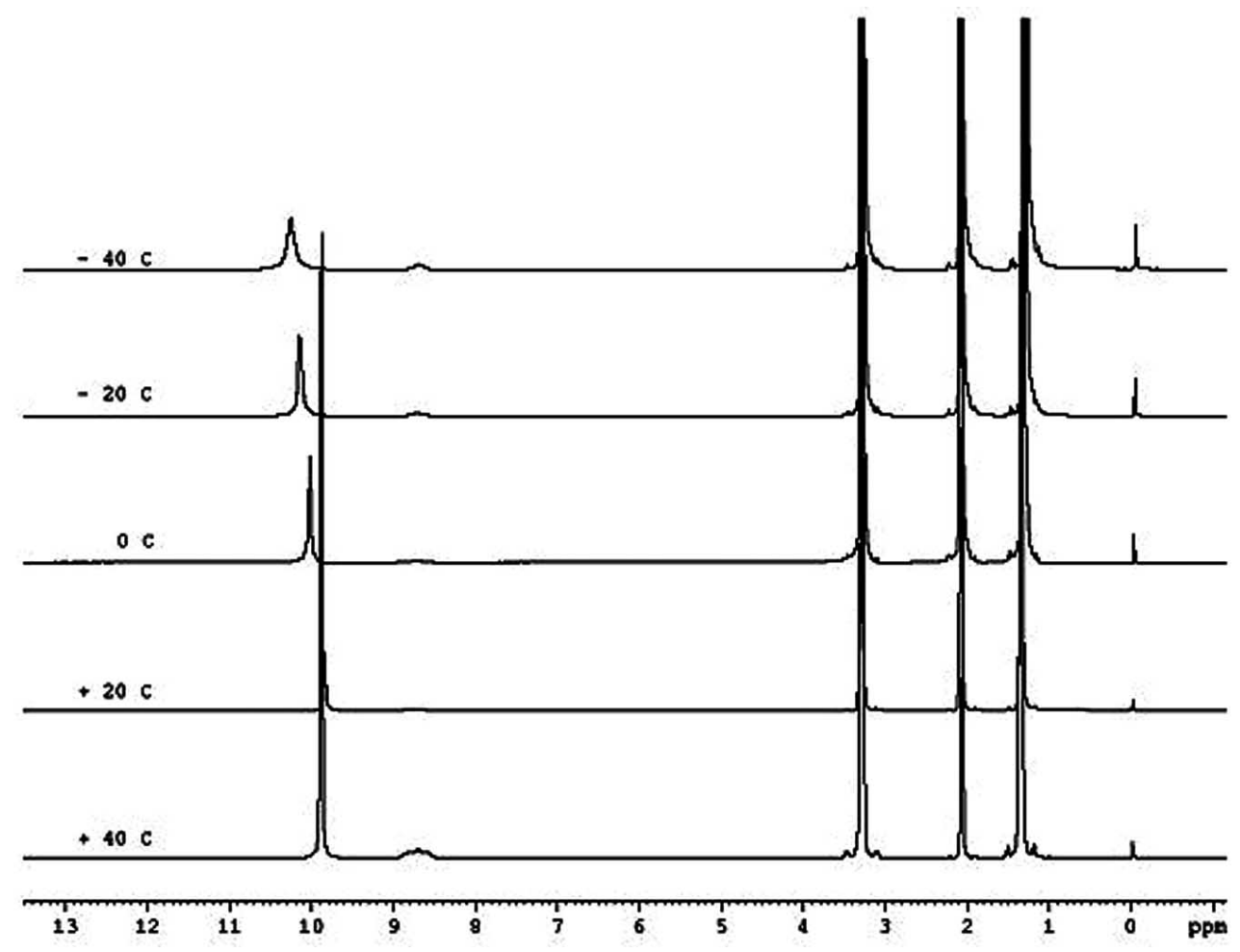

Fig. (3). ${ }^{1} \mathrm{H}$ NMR spectra of triethylamine $4 \mathrm{HF}$ adduct recorded at various temperatures.

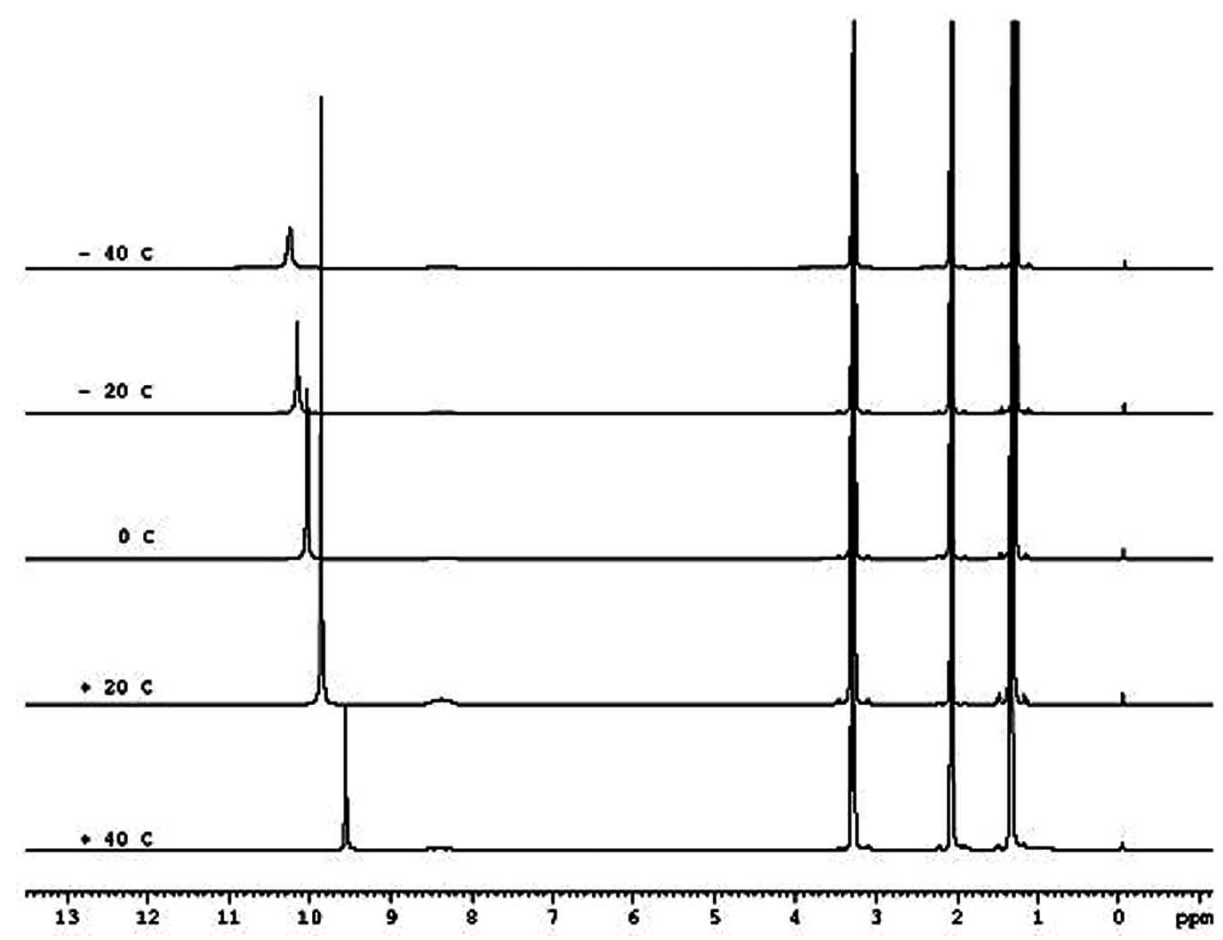

Fig. (4). ${ }^{1} \mathrm{H}$ NMR spectra of triethylamine $5 \mathrm{HF}$ adduct recorded at various temperatures.

been shown in [12] in that hydrogen bond lengths measured by X-ray diffraction correlates with the chemical shift of the proton [12]. Further it has been reported in the aforementioned reference that hydrogen bonds decrease in length from $3.0 \AA$ to $2.45 \AA$. This indicates the trend of strength of hydrogen bond. The trend proceeds from weak to strong. Then the proton becomes more de-shielded and this is the reason for resonance shift towards the downfield as in the present case approaching a value of $18 \mathrm{ppm}$ (from $3 \mathrm{HF}$ to $5 \mathrm{HF}$ ) against $21 \mathrm{ppm}$ reported in the aforementioned reference. The reason for de-shielding is the increasing the length of the covalent bond $\mathrm{N}-\mathrm{H}$ moiety of the N-H-F hydrogen bond as the overall hydrogen bond length decreases. This lengthening attenuates the major shielding provided by the sigma bonding electron pair. 


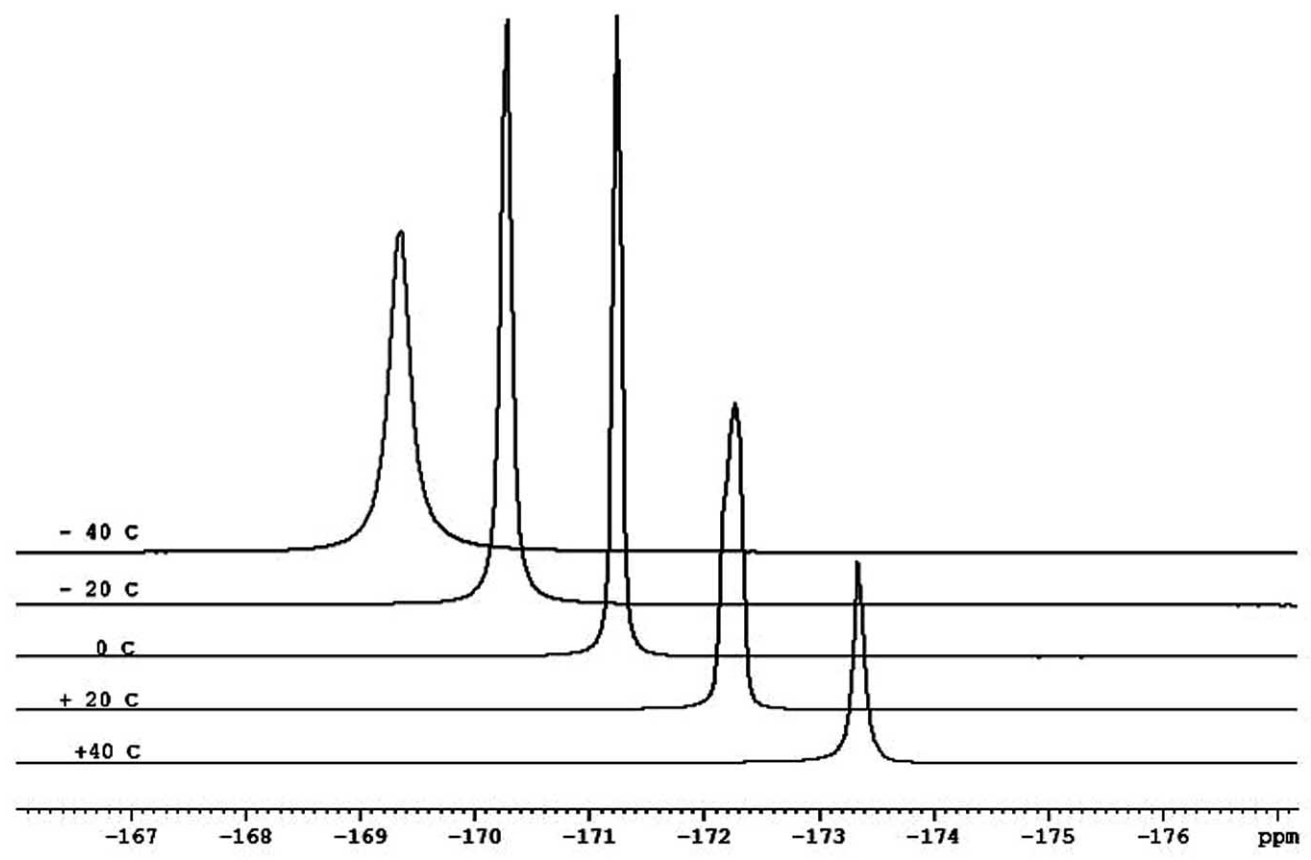

Fig. (5). ${ }^{19} \mathrm{~F}$ NMR spectra of triethylamine $3 \mathrm{HF}$ adduct recorded at various temperatures.

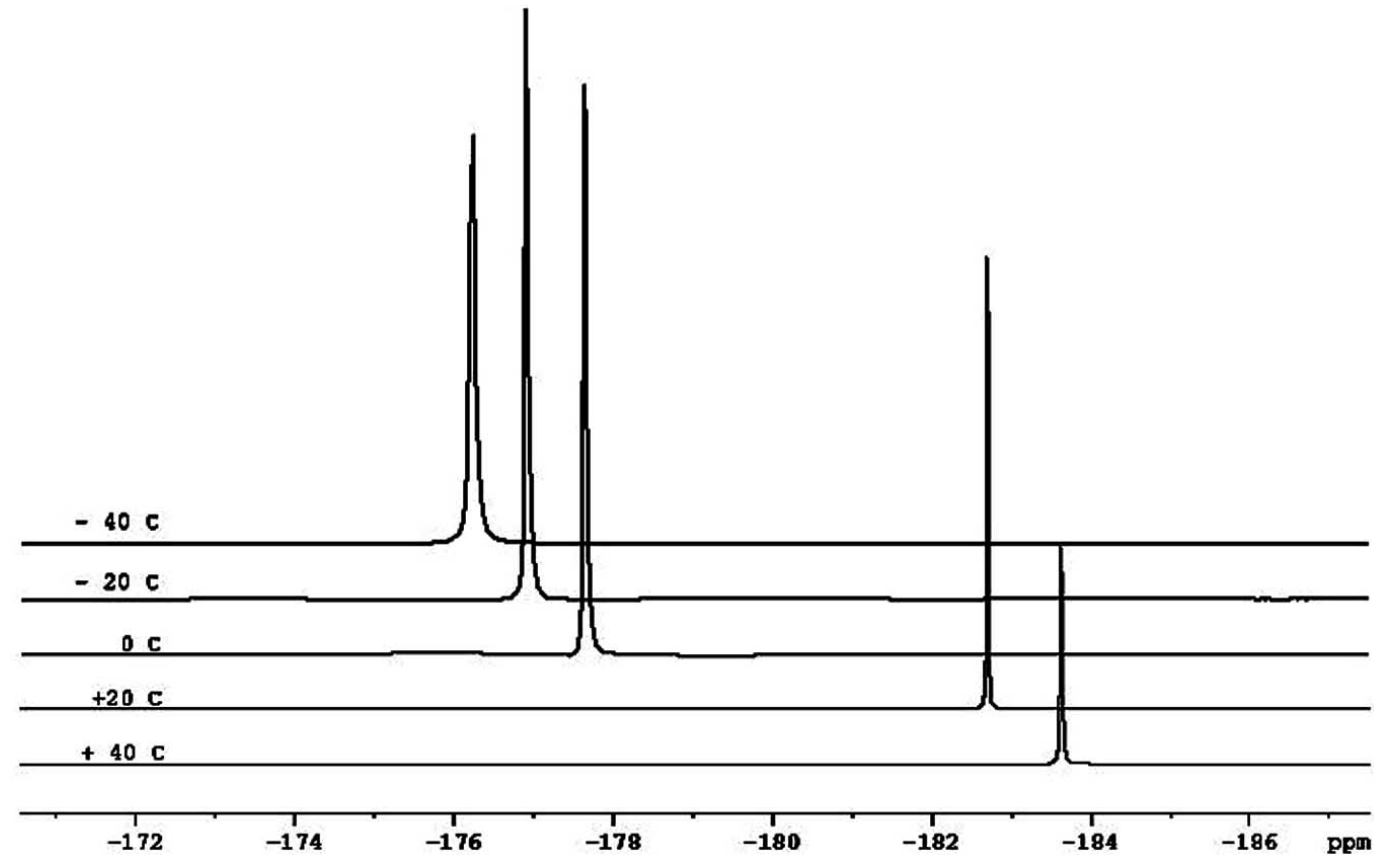

Fig. (6). ${ }^{19}$ F NMR spectra of triethylamine $4 \mathrm{HF}$ adduct recorded at various temperatures.

A rigorous highly useful correlation of N-H-F hydrogen bond lengths $\mathrm{D}$, measured by small molecule high resolution X-ray crystallography, with chemical shifts $\delta$, determined by solid state NMR, is reported in [13]. It is justifiable to have long weak hydrogen bonds with an empirical equation provided in [14]. To get the value of $D$ from chemical shift data the equation used in is $\mathrm{D}=5.04-1.16 \ln (\delta)+0.0447(\delta)$ [14]. And using this equation the chemical shift data were inserted in the equation and bond lengths in Angstrom unit have been calculated and Fig. (16) shows the exponential decrease of bond length versus increase of chemical shifts. From the figures it is seen that bond lengths decrease as chemical shift value increases. This indicates the trend of strength of hydrogen bond which proceeds from weak to strong and the proton becomes more de-shielded. The resonance is shifted downfield.

Hydrogen bridge, the parameter characterizing the geometry, dentoes the distances between nitrogen and hydrogen and hydrogen and fluorine. With increase of temperature the broader peak becomes sharper and the intensity also gets increased to a certain temperature ,viz, $0^{0}$ $\mathrm{C}$ and then it becomes broader and also lesser as temperature is higher. In general, the peaks shift to downfield. Spin lattice relaxation is low at lower temperature $350 \mathrm{~ms}$ compared to $908 \mathrm{~ms}$ at higher temperature $+40^{\circ} \mathrm{C}$. 
Fig. (5) further elucidates the formation of $\mathrm{NH}$ bond and eliminates the interaction of hydrocarbon with HF. This is clearly evident from the stationary peaks of methyl and methylene compared to $\mathrm{NH}$ and $\mathrm{HF}$ bonds. At $40^{\circ} \mathrm{C}$ the $\mathrm{HF}$ bond is clearly seen whereas it slowly reduces and diminishes as temperture goes down and slight formation of $\mathrm{NH}$ interaction is indicated from the downfield shift.

Fig. (6) shows the interaction of HF with triethylamine as more of HF is coming into contact with parent molecule and here the clear diminishing of the peak HF compared to the $\mathrm{NH}$ as temperature goes down. Fig. (7) further clearly indicates the aforementioned behavior and confirms the lone pair of nitrogen role in the formation of complexes with HF. Figs. $(\mathbf{8}, 9,10,11 \& 12)$ clearly demonstrated the aforementioned discussion. An increase in the interaction between neighboring fluorine is responsible for the lower field reso- nance and this fact is true in increasing the de-shielding and increasing the coupling constants due to the interaction of fluorine. Each downfield shift is greater than 5 to $10 \mathrm{ppm}$. Nuclear spin lattice relaxation measurements are known to be an effective tool in studying complexes formed with HF by triethylamine. The interpretation of spin lattice relaxation is usually based on the analysis of fluctuations of dipoledipole interactions in hydrocarbon and fluorocarbon groups and of anisotropic electron-nuclear interactions responsible for chemical shielding anisotropy. These fluctuations are caused by molecular mobility. In the complexes of triethylamine with fluorine complexes there is an origin of paramagnetic defects and these arise from unpaired electrons. Such defects are usually created during the sample preparation process. The interaction between nuclear and electron spins is known to strongly influence the nuclear spin lattice

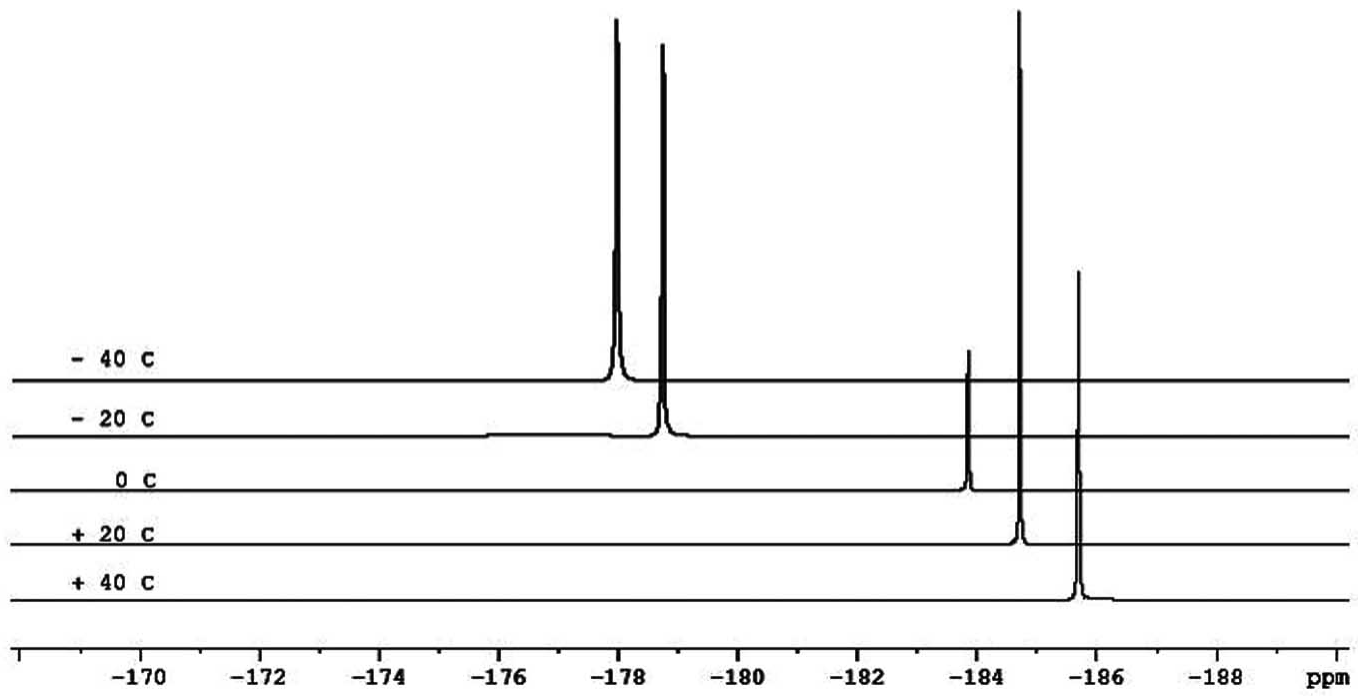

Fig. (7). ${ }^{19}$ F NMR spectra of triethylamine $5 \mathrm{HF}$ adduct recorded at various temperatures.

$-40 C$ (2H)

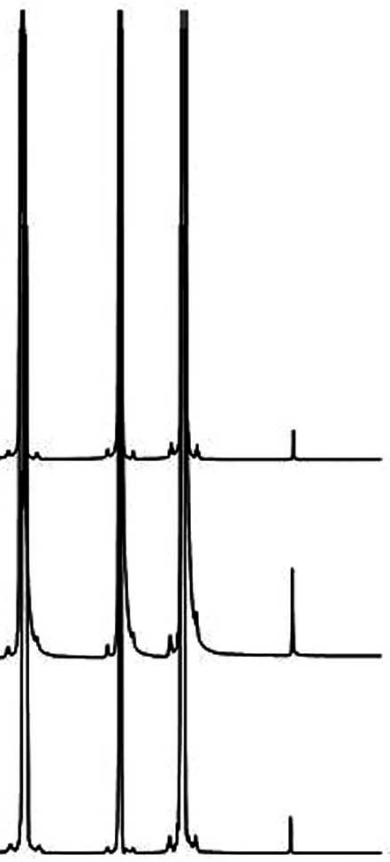

Fig. (8). ${ }^{1} \mathrm{H}$ NMR spectra of triethylamine $\mathrm{nHF}$ adduct recorded at $-40 \mathrm{c}$. 


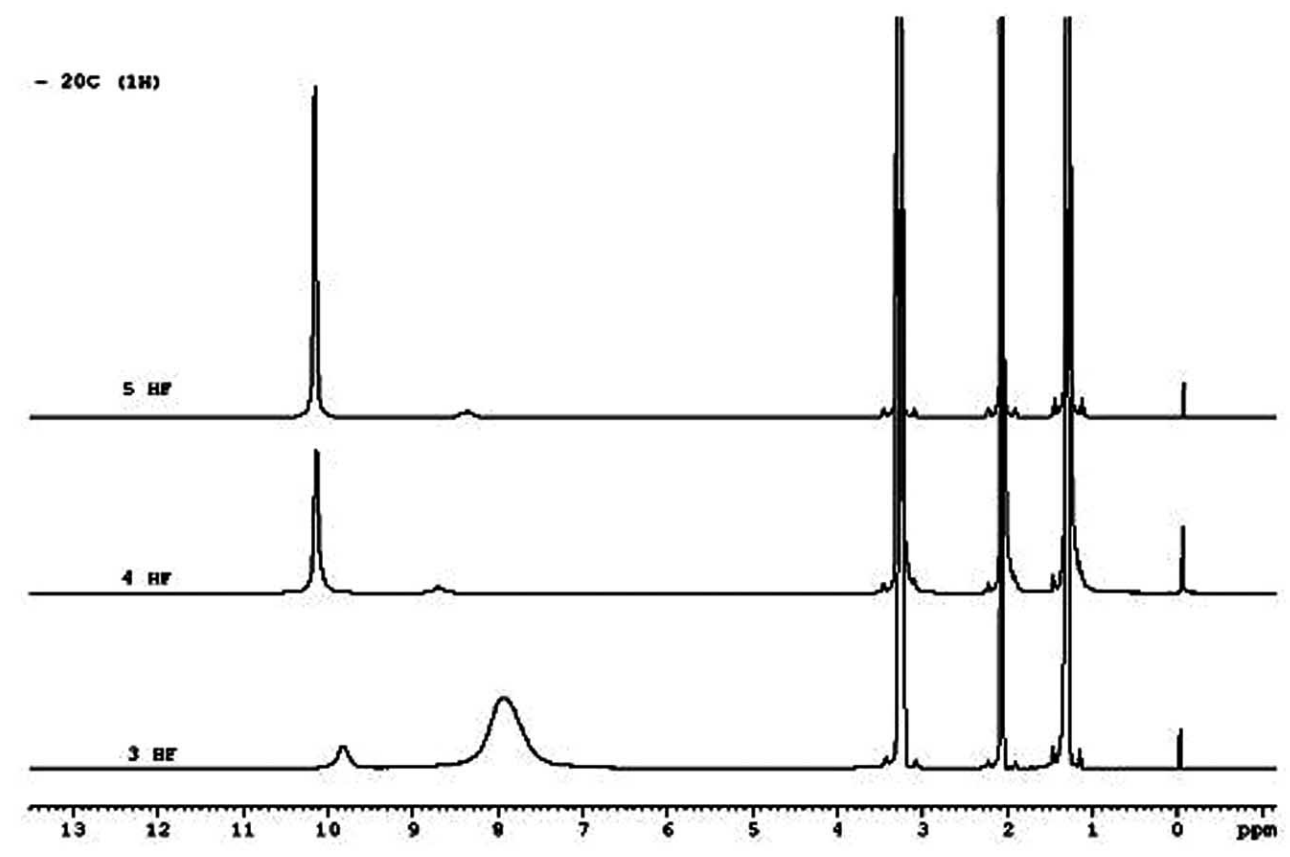

Fig. (9). ${ }^{1} \mathrm{H}$ NMR spectra of triethylamine $\mathrm{nHF}$ adduct recorded at $-20 \mathrm{c}$.

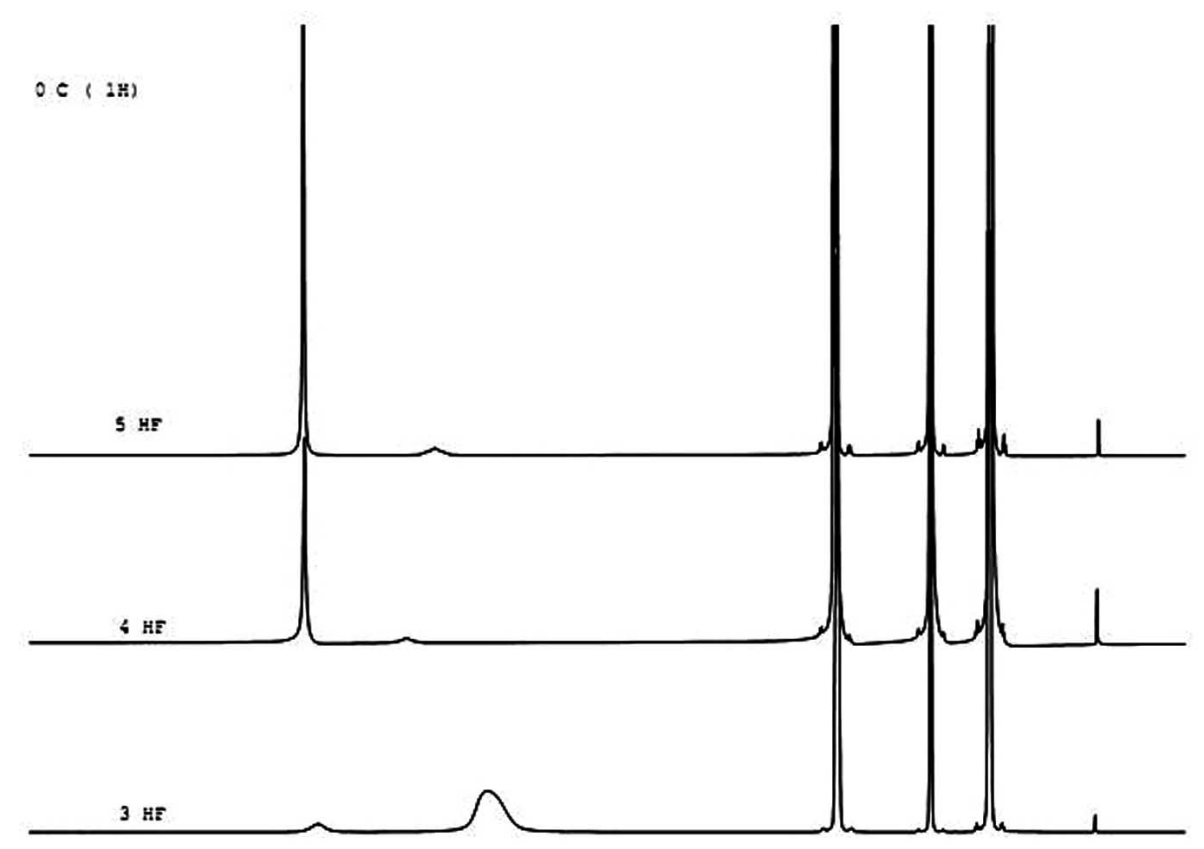

Fig. (10). ${ }^{1} \mathrm{H}$ NMR spectra of triethylamine $\mathrm{nHF}$ adduct recorded at $0 \mathrm{c}$.

relaxation. Another contribution might come from the interaction of nuclear spins with adsorbed para magnetic nitrogen molecules.

Temperature dependence of spin-lattice relaxation rate: Nuclear spin lattice relaxation rate $\mathrm{R}_{1}=\mathrm{T}_{1^{-}}{ }^{1}$ is determined by the expression $[15,16]$.

$\mathrm{R}_{1}=\mathrm{R}_{1 \mathrm{~F}}+\mathrm{R}_{1 \mathrm{~F}-\mathrm{X}}$

where $\mathrm{R}^{1 \mathrm{~F}}=\mathrm{T}_{1 \mathrm{~F}}{ }^{-1}$ is the contribution to the spin lattice relaxation caused by dipole-dipole coupling between spins of magnetic nuclei in rotating complexes and $\mathrm{R}_{1 \mathrm{~F}-\mathrm{X}}=\mathrm{T}_{1 \mathrm{~F}-\mathrm{x}}{ }^{-1}$ is the contribution caused by the dipole-dipole interaction of fluorine spins and magnetic moments of paramagnetic defects. The first contribution is known to be described by the Bloemergen-Purcell-Pound (BPP) theory and is given by the expression [17].

$\left.\mathrm{R}_{1 \mathrm{~F}}=\mathrm{T}_{1 \mathrm{~F}}{ }^{-1}=2 / 3\left\{2 \Delta \mathrm{M}_{2 \mathrm{~F}}\right\} / 3 \mathrm{w}_{0}\right\}\left\{\left(\mathrm{x} / 1+\mathrm{x}^{2}\right)+\left(4 \mathrm{x} / 1+4 \mathrm{x}^{2}\right)\right\}(1)$

where $\mathrm{w}_{0}$ is the Larmor frequency and $\tau \mathrm{c}$ is the correlation time of the molecular rotation and $\mathrm{x}=\mathrm{w}_{\mathrm{o}} \tau_{0}$

Spin lattice relaxation ( $\mathbf{T}_{\mathbf{1}}$ measurement) versus temperature values for $3 \mathrm{HF}, 4 \mathrm{HF}$ and $5 \mathrm{HF}$ given in the Table $\mathbf{1}$, also plotted as graph which is shown in the Fig. (13) for 3HF. From this figure the minimum point is noted. From the minimum value symmetrical $\mathrm{V}$ shaped curves were drawn and this is shown as extended curves in the figures (The 


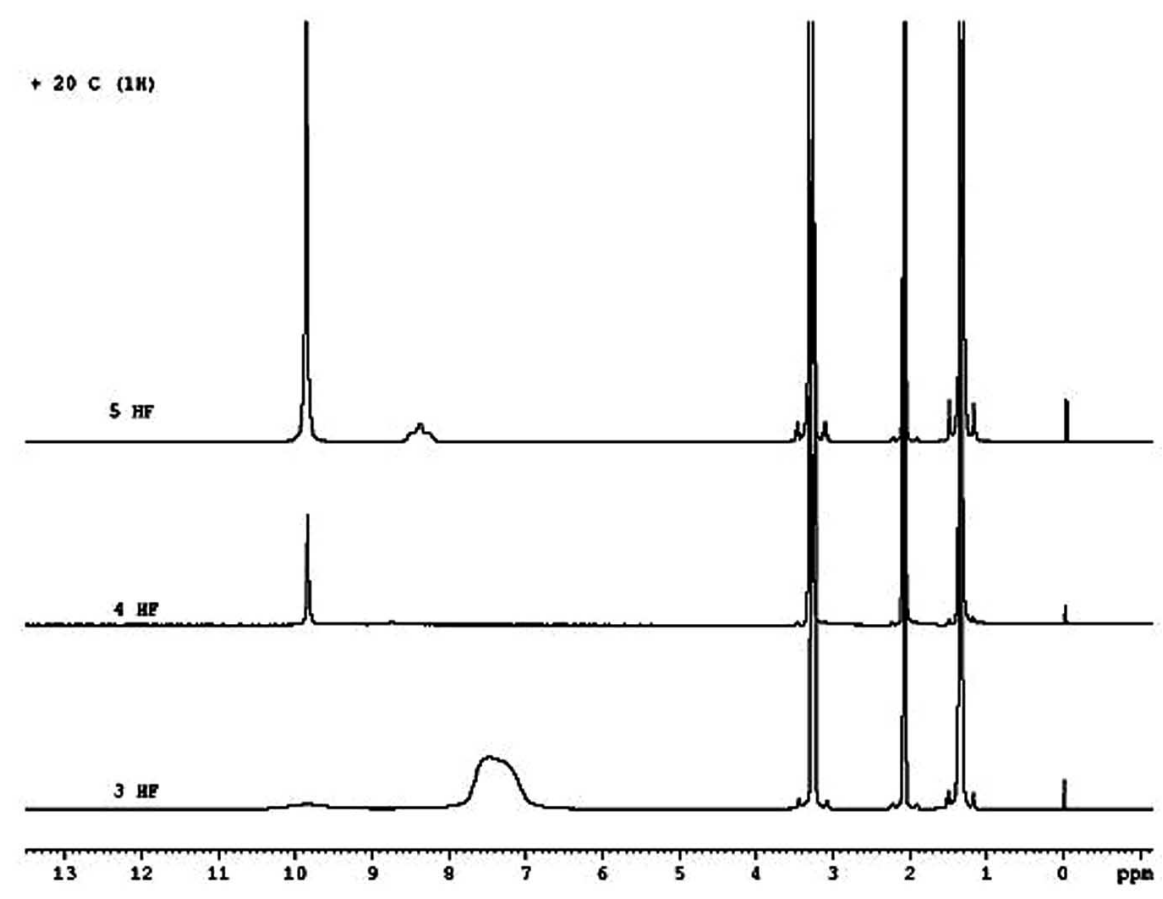

Fig. (11). ${ }^{1} \mathrm{H}$ NMR spectra of triethylamine $\mathrm{nHF}$ adduct recorded at $+20 \mathrm{c}$.

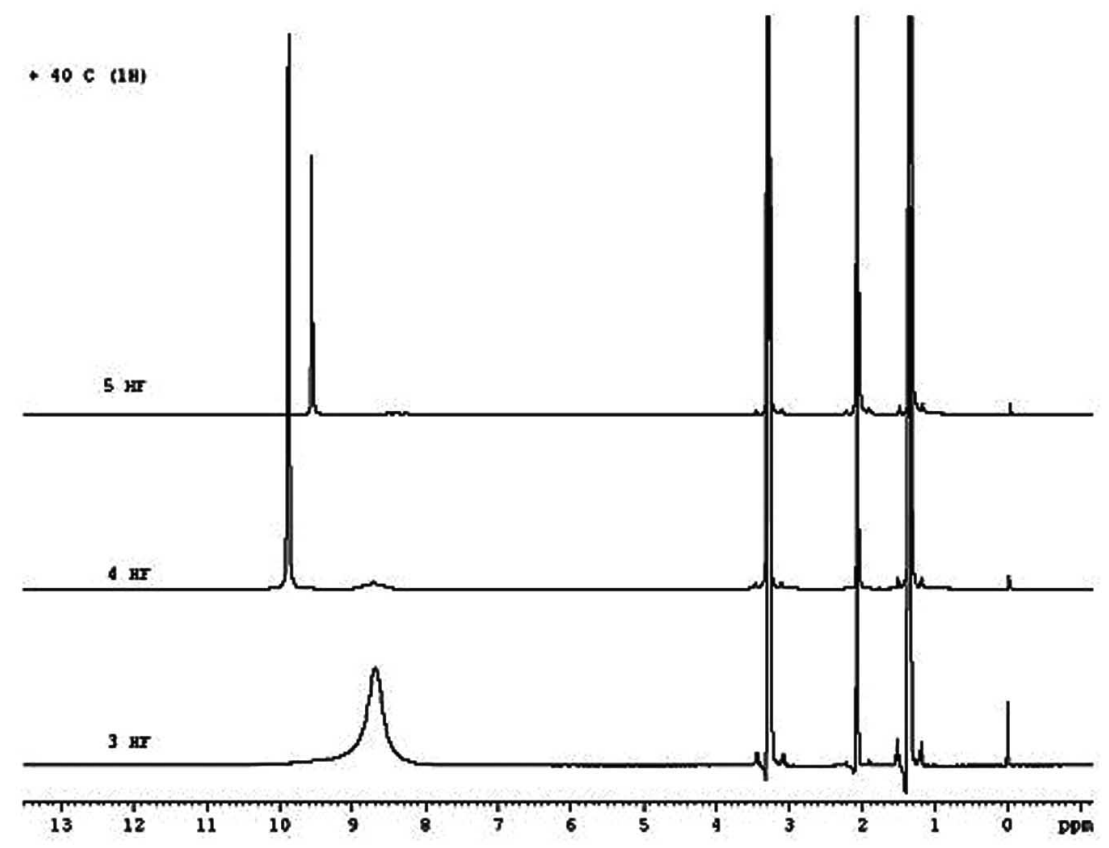

Fig. (12). ${ }^{1} \mathrm{H}$ NMR spectra of triethylamine $\mathrm{nHF}$ adduct recorded at $+40 \mathrm{c}$.

values are extrapolated outside the range of experiments). This is shown in the Figs. (13-15) and consolidated results are shown in Fig. (16). This figure is a semi logarithmic plot of spin lattice relaxation at different temperature at the larmour frequency of $\omega_{\mathrm{F}}$. The extended curve corresponds to a higher frequency than $\omega_{\mathrm{F}}$.

The corresponding ${ }^{19} \mathrm{~F} \mathrm{~T}_{1}$ minimum value in the Fig. (16) decreases with increasing the fluorination of the complex and increasing with temperature and these data are given in the Table 3. This also suggests that location of $T_{1}$ minima on the variable temperature relaxation curves directly depends on molecular mobility. This suggests that molecular motions are fast as the triethylamine is added with more HF. This
Table 1. T1 Measurements for the Nuclii ${ }^{19} \mathrm{~F}$ is Provided

\begin{tabular}{|l|c|c|c|}
\hline Temperature & \multicolumn{3}{|c|}{$\mathbf{T}_{\mathbf{1}}$ M Milli Seconds } \\
\hline & $\mathbf{3 H F}$ & $\mathbf{4 H F}$ & $\mathbf{5 H F}$ \\
\hline \hline $40^{\circ} \mathrm{C}$ & 909.8 & 210.7 & 260.2 \\
\hline $20^{\circ} \mathrm{C}$ & 525.5 & 393.8 & 407.7 \\
\hline $0^{\circ} \mathrm{C}$ & 556.5 & 823.3 & 810.6 \\
\hline$-20^{\circ} \mathrm{C}$ & 464.1 & 923.9 & 773.2 \\
\hline$-40^{\circ} \mathrm{C}$ & 351.8 & 707 & 489.9 \\
\hline
\end{tabular}




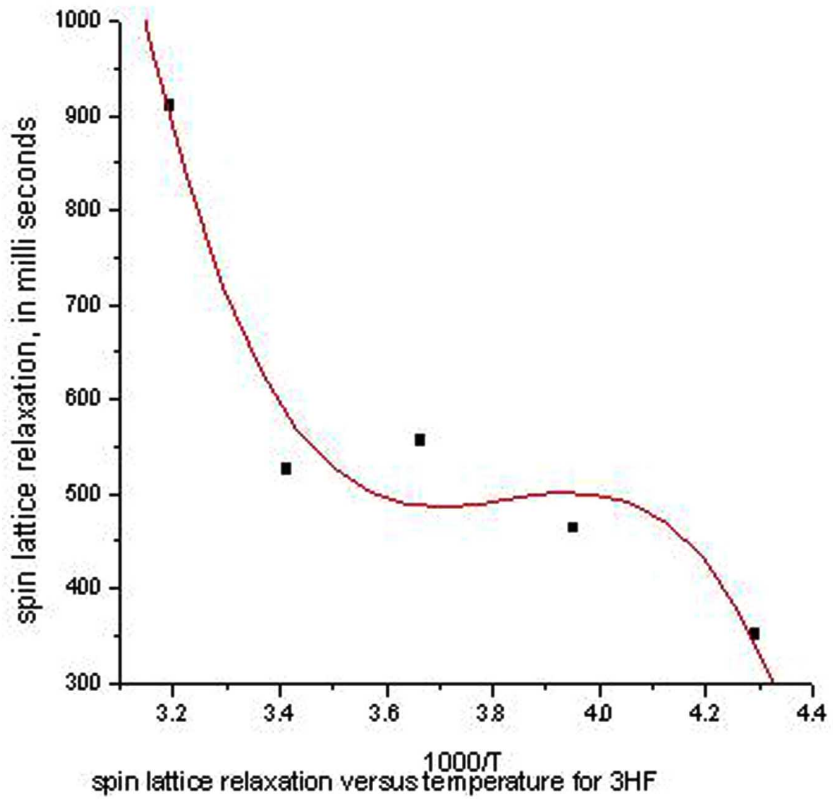

Fig. (13). Spin lattice relaxation versus temperature for $3 \mathrm{HF}$.

Table 2. Bond Length Versus Chemical Shifts

\begin{tabular}{|c|c|}
\hline $\boldsymbol{\delta}$ & $\mathbf{D}$ \\
\hline \hline 2 & 4.288418 \\
\hline 4 & 3.580699 \\
\hline 6 & 3.199759 \\
\hline 8 & 2.955448 \\
\hline 10 & 2.786001 \\
\hline 12 & 2.663908 \\
\hline 14 & 2.574493 \\
\hline 16 & 2.508997 \\
\hline 18 & 2.461769 \\
\hline
\end{tabular}

also suggests that the tri ethyl complex with $3 \mathrm{HF}$ is different from $4 \mathrm{HF}$ and $5 \mathrm{HF}$, where in $3 \mathrm{HF}$ there is still a link of hydrogen bonding with nitrogen is expected and in $4 \mathrm{HF}$ and 5 HF this has shifted to hydrogen fluorine bonding rather nitrogen hydrogen link.

When HF interacted with a strong proton acceptor, namely, nitrogen which has a lone pair of electrons in tri ethyl amine, the conventional hydrogen bonding will be the dominant interaction. The strength of this interaction will increase upon the addition of HF to triethylamine. Thus as the main goal of the present work in this investigation is to use ${ }^{1} \mathrm{H}$ and ${ }^{19} \mathrm{~F}$ NMR to understand the formation of $\mathrm{HF}$ bridges in aprotic environments and this is partly fulfilled in the sense that ${ }^{19} \mathrm{~F}$ NMR is able to give a clue of the formation of $\mathrm{HF}$ bond as HF molecules are added to triethylamine.

The terms $\mathbf{r}_{\mathrm{AH}}$ and $\mathrm{r}_{\mathrm{BH}}$ denote the distance between $\mathrm{N}-\mathrm{H}$ and $\mathrm{H}-\mathrm{F}$. There is a fast exchange between the hydrogen bond and bulk HF tri ethyl anion. When the exchange is suppressed spectrum displays two signals and there is no such

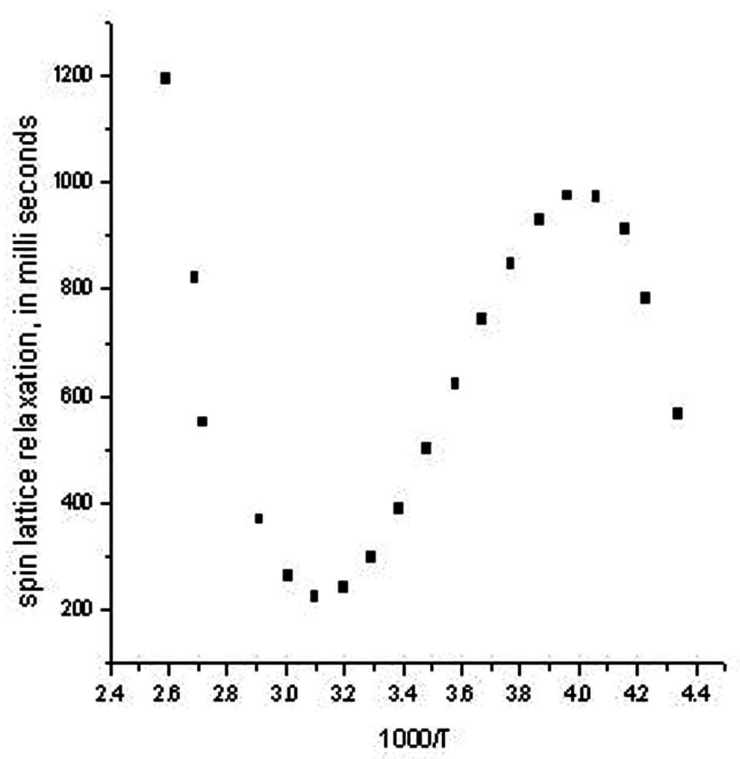

spin lattice relaxation versus temperature for $4 \mathrm{HF}$ extended graph

Fig. (14). Spin lattice relaxation versus temperature for $4 \mathrm{HF}$ extended graph.

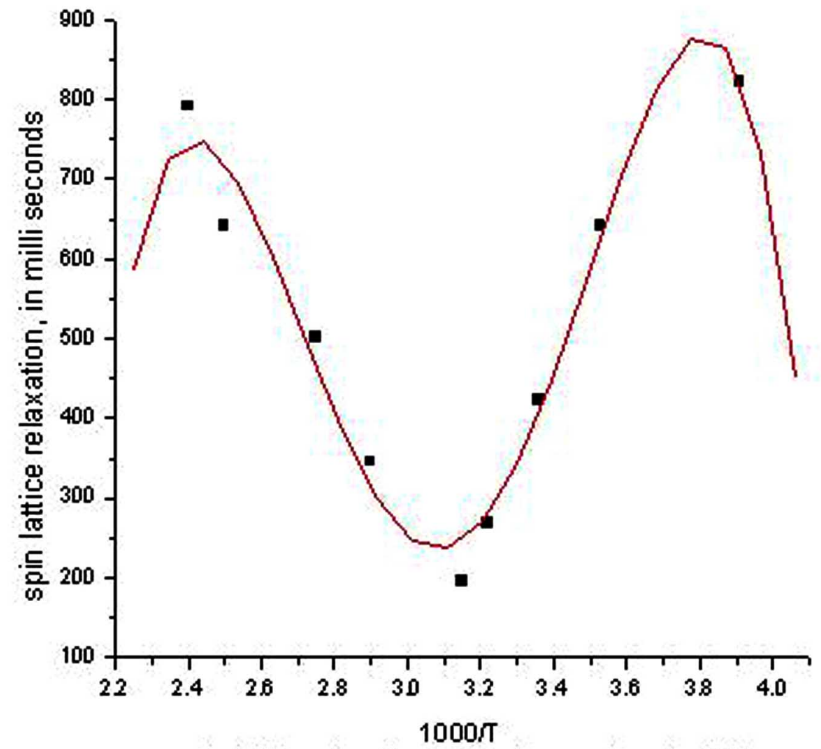

spin lattice relaxation versus tem perature for 5HF

Fig. (15). Spin lattice relaxation versus temperature for $5 \mathrm{HF}$ extended graph.

splitting occurs in the present study and this indicates two kinds of interactions viz either $\mathrm{N}-\mathrm{H}$ bond or $\mathrm{H}-\mathrm{F}$ bond formation.

Upon increase of $\mathrm{H}-\mathrm{F}$ content the signal at $>180 \mathrm{ppm}$ becomes dominant. While the intensity of the signal at 170 ppm triethylamine is strongly reduced. When $\mathrm{HF}$ is in excess, the spectrum displays only signal at $186 \mathrm{ppm}$ whose chemical shift does not depend on the HF content. As long as triethylamine to $\mathrm{HF}$ content is 3 or 4 the spectra contain exclusively $3 \mathrm{HF}$ or $4 \mathrm{HF}$ species. In contrast, when this ratio is below 4 the corresponding spectra displays the only signal at 170 to $180 \mathrm{ppm}$. 


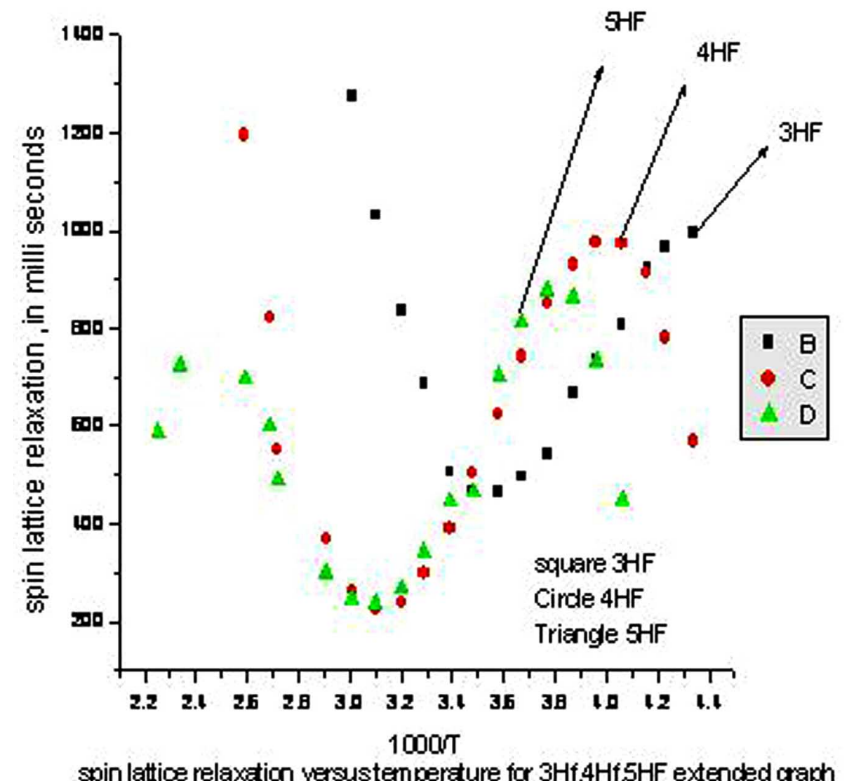

Fig. (16). Spin lattice relaxation versus temperature for $3 \mathrm{HF} .4 \mathrm{HF}$ and $5 \mathrm{HF}$ as extended graph.

In aprotic environment protons of solitary HF molecules resonate around 170 to $186 \mathrm{ppm}$ while $\mathrm{HF}$ micro drops give rise to a peak at $176 \mathrm{ppm}$ typical for HF. Water molecules involving stronger hydrogen bonds are characterized by higher values of ${ }^{1} \mathrm{H}$ chemical shift. Generally the protons and hydrogen bonds exchange between different acid base complexes in solution is very fast on the NMR time scale. At room temperature it is not possible to identify their structure and properties.

The position and intensity of the peak depend strongly on temperature. At room temperature $\mathrm{HF}$ molecules become involved in more or less stable hydrogen bonded complexes with each other and triethylamine. The exchange between different structures is still too fast to suppress on averaging but the peak intensity becomes broader. The line broadening is accompanied by a dramatic reduction of the signal and this is due to HF precipitation from the complex with base. The chemical shift asymptotically approach to a value of 18 to $21 \mathrm{ppm}$.

Proton bonding ability of HF molecule bonded to the base increases due to the mutual cooperative ability with other HF molecules and is associated with clusters. A shortening of nHF bond results in the length of the other. This can be explained by stronger basicity. The chemical shift changes of individual hydrogen atoms. High field shift as already discussed, indicates an increased electron density of the hydrogen atoms and this weakens of the hydrogen bonding interaction. It is also clear that $3 \mathrm{HF}$ tends to form $\mathrm{N}-\mathrm{H}$ bond and in the case of 4HF and 5HF it is clear that there is a deviation from bond formation and this tends to wards H-F and N-H-F bond slowly leans towards fluorine and this is clearly indicated from the fig. by the formation of minimum occurs at a particular temperature.

Towards this argument an attempt has been made to calculate the bond distance from the NMR data. Using the equation (1), as provided in [18]. Homo nuclear coupling corresponds to interactions of nuclei of the same sort, when two coupled nuclei are identical,

For example, the strength of the protons in homo nuclear dipolar coupling $\mathrm{DC}_{\mathrm{H}-\mathrm{H}}$ is written as

$\left.\mathrm{DC}_{\mathrm{H}-\mathrm{H}}=0.3\left(\mu_{0} / 4 \pi\right)^{2} \gamma_{\mathrm{H}}{ }^{4} \hbar^{2} \mathrm{r}(\mathrm{H}-\mathrm{H})\right)^{-6}$

and if the magnetic dipole of one nucleus, for example, a proton, can interact with the magnetic dipole of nucleus $\mathrm{F}$, other than proton then the strength of this hetero nuclear dipolar coupling $\mathrm{DC}_{\mathrm{H}-\mathrm{F}}$ is written as

$\mathrm{DC}_{\mathrm{H}-\mathrm{F}}=4 / 30\left(\mu_{0} / 4 \pi\right)^{2} \gamma_{\mathrm{H}}^{2} \gamma_{\mathrm{F}}^{2} \hbar^{2} \mathrm{I}_{\mathrm{B}}\left(\mathrm{I}_{\mathrm{B}}+1\right) \mathrm{r}(\mathrm{H}-\mathrm{F})^{-6}$

In these, the values used for the calculations are given in Table 4

Bond distance in $3 \mathrm{HF}$ is calculated and the value is $=2.6 \AA$ Bond distance in $4 \mathrm{HF}$ is calculated and the value is $=5.6 \AA$

Bond distance in $5 \mathrm{HF}$ is calculated and the value is $=5.66 \AA$

Table 3. 1/T1 Values at Minimum Temperature

\begin{tabular}{|c|c|c|c|}
\hline Complex & Minimum Temp 1000/T & Minimum Temp in K & 1/T1 in Milli Seconds \\
\hline \hline $3 \mathrm{HF}$ & 3.58 & 279 & 465 \\
\hline $4 \mathrm{HF}$ & 3.2 & 312 & 240 \\
\hline $5 \mathrm{HF}$ & 3.1 & 322 & 224 \\
\hline
\end{tabular}

Table 4. Values Used in the Calculation for Bond Distances

\begin{tabular}{|c|c|c|c|}
\hline Nucleus & Spin & NMR Frequency $v(\mathrm{MHz})$ at $\mathrm{B}_{0} 2.4388 \mathrm{~T}$ & $\gamma\left(10^{7} \operatorname{radT}^{-1} \mathrm{~s}^{-1}\right)$ \\
\hline${ }^{1} \mathrm{H}$ & $1 / 2$ & 100 & 26.752 \\
\hline${ }^{14} \mathrm{~N}$ & 1 & 7.22 & 1.934 \\
\hline${ }^{19} \mathrm{~F}$ & $1 / 2$ & 94.08 & 25.18 \\
\hline
\end{tabular}




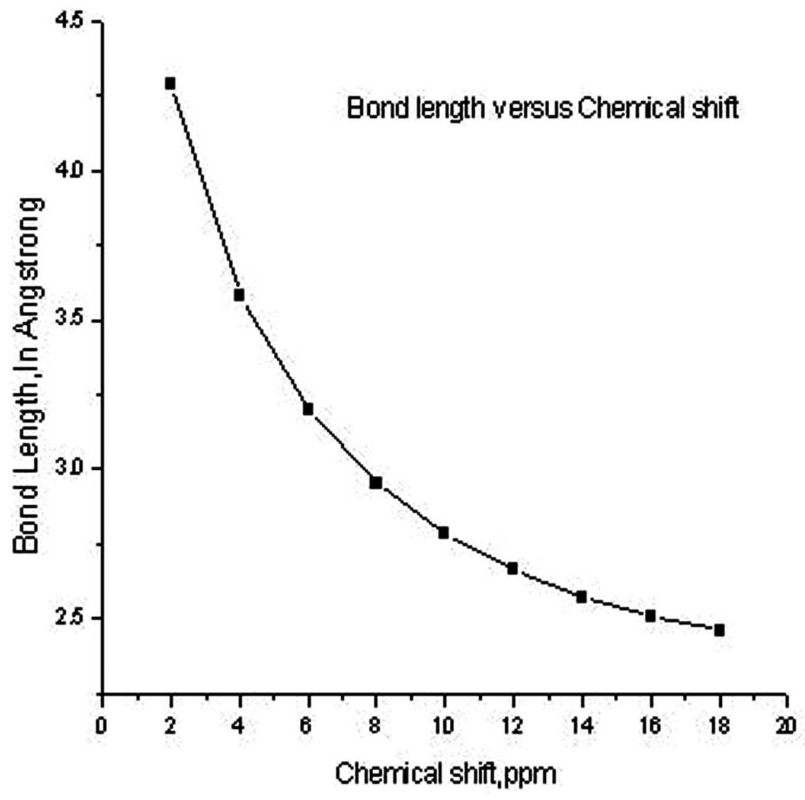

Fig. (17). Plot of Bond length versus chemical shifts.

This bond distance is compared with the chemical shift calculations provided in the Fig. (17), and these data are given in Table 2. The bond distance of $2.6 \AA$ corresponds to $3 \mathrm{HF}$ whereas the bond distance for $4 \mathrm{HF}$ and $5 \mathrm{HF}$ is slightly higher $5.6 \AA$ compared to $4.2 \AA$ for $4 \mathrm{HF}$ and $5 \mathrm{HF}$ from chemical shift data. This higher value is due to experimental and calculation error and the magnitude should not be mattered in this type and only the trend is to be taken and hence the assumption that fluorination of tri ethyl amine leads to different adducts of HF and higher adducts HF bond is predominant compared to lower adducts of HF where N-H-F bond is expected.

\section{CONCLUSIONS}

Fluorination takes place as HF adducts and not as C-F bond. From NMR data it is possible to identify three different adducts to triethylamine. From chemical shift values it is possible to distinguish the three adducts. From NMR data it is possible to calculate bond distance of homo nuclear and hetero nuclear nuclei. ${ }^{1} \mathrm{H}$ NMR chemical shift data of three adducts were measured at five different temperatures are given below:

\section{HF}

$$
\begin{aligned}
& 0^{\circ} \mathrm{C}=1.32(\mathrm{t}, 3 \mathrm{H}), 3.26(\mathrm{~d}, 2 \mathrm{H}),-171.2(\mathrm{~s}, \mathrm{HF}) \\
& 20^{\circ} \mathrm{C}=1.34(\mathrm{t}, 3 \mathrm{H}), 3.25(\mathrm{~m}, 2 \mathrm{H}),-172.2(\mathrm{~s}, \mathrm{HF}) \\
& 40^{\circ} \mathrm{C}=1.36(\mathrm{t}, 3 \mathrm{H}), 3.26(\mathrm{~m}, 2 \mathrm{H}),-173.3(\mathrm{~s}, \mathrm{HF}) \\
& -20^{\circ} \mathrm{C}=1.31(\mathrm{t}, 3 \mathrm{H}), 3.25(\mathrm{~m}, 2 \mathrm{H}),-170.2(\mathrm{~s}, \mathrm{HF}) \\
& -40^{\circ} \mathrm{C}=1.30(\mathrm{t}, 3 \mathrm{H}), 3.24(\mathrm{~m}, 2 \mathrm{H}),-169.3(\mathrm{~s}, \mathrm{HF})
\end{aligned}
$$

\section{$4 \mathbf{H F}$}

$0^{\circ} \mathrm{C}=1.32(\mathrm{t}, 3 \mathrm{H}), 3.28(\mathrm{~m}, 2 \mathrm{H}),-177.6(\mathrm{~s}, \mathrm{HF})$

$20^{\circ} \mathrm{C}=1.33(\mathrm{t}, 3 \mathrm{H}), 3.28(\mathrm{~m}, 2 \mathrm{H}),-178.4(\mathrm{~s}, \mathrm{HF})$ $40^{\circ} \mathrm{C}=1.34(\mathrm{t}, 3 \mathrm{H}), 3.28(\mathrm{~m}, 2 \mathrm{H}), 9.8(\mathrm{~s}, \mathrm{NH}),-178.9(\mathrm{~s}, \mathrm{HF})$,

$-20^{\circ} \mathrm{C}=1.30(\mathrm{t}, 3 \mathrm{H}), 3.27(\mathrm{~m}, 2 \mathrm{H}),-176.8(\mathrm{~s}, \mathrm{HF})$

$-40^{\circ} \mathrm{C}=1.29(\mathrm{t}, 3 \mathrm{H}), 3.27(\mathrm{~m}, 2 \mathrm{H}),-176.2(\mathrm{~s}, \mathrm{HF})$

5 HF

$0^{\circ} \mathrm{C}=1.30(\mathrm{t}, 3 \mathrm{H}), 3.27(\mathrm{~m}, 2 \mathrm{H}), 10.03(\mathrm{~s}, \mathrm{NH}),-183.8(\mathrm{~s}, \mathrm{HF})$

$20^{\circ} \mathrm{C}=1.32(\mathrm{t}, 3 \mathrm{H}), 3.28(\mathrm{~m}, 2 \mathrm{H}), 9.8(\mathrm{~s}, \mathrm{NH}),-184.7(\mathrm{~s}, \mathrm{HF})$

$40^{\circ} \mathrm{C}=1.33(\mathrm{t}, 3 \mathrm{H}), 3.28(\mathrm{~m}, 2 \mathrm{H}), 9.7$ (s, NH), -185.6 (s, HF),

$-20^{\circ} \mathrm{C}=1.29(\mathrm{t}, 3 \mathrm{H}), 3.27(\mathrm{~m}, 2 \mathrm{H}),-178.7(\mathrm{~s}, \mathrm{HF})$

$-40^{\circ} \mathrm{C}=1.28(\mathrm{t}, 3 \mathrm{H}), 3.20(\mathrm{~d}, 2 \mathrm{H}),-177.9(\mathrm{~s}, \mathrm{HF})$

\section{ACKNOWLEDGEMENT}

The authors wish to thank profusely Director CECRI for his knid encouragement in this work. One of the authors wishes to thank Dr. R. Rangarajan Chancellor and chairman Vel Tech of Dr. RR. \& Dr. SR. tech university Avadi, Chennai for his constant and continued support to work towards this paper.

\section{CONFLICT OF INTEREST}

None declared.

\section{REFERENCES}

[1] Welch JT. Advances in the preparation of biologically active organofluorine compounds. Tetrahedron 1987; 43: 3123-97.

[2] Rozen S, Filler R. $\alpha$-Fluorocarbonyl compounds and related chemistry. Tetrahedron 1985; 41: 1111-53.

[3] Purrington ST, Woodard DL. Preparation of alpha-fluoro carboxylic-acids and derivatives. J Org Chem 1990; 55: 3423-4.

[4] Fujisawa $H$, Takeuchi Y. Simple procedure for preparation of $\alpha$ fluoro esters by fluorination of ester enol silyl ethers with perchloryl fluoride. J Fluorine Chem 2002; 117: 173-6.

[5] Noel M, Suryanarayanan V, Chellammal S. A review of recent developments in the selective electrochemical fluorination of organic compounds. J Fluorine Chem 1997; 83: 31-40.

[6] Dawood KM. Electrolytic fluorination of organic compounds. Tetrahedron 2004; 60; 1435-51.

[7] Noel M, Suryanarayanan V. Current approaches to the electrochemical synthesis of organo-fluorine compounds. J Appl Electrochem 2004; 34: 357-69.

[8] Fuchigami T, Tajima T. Highly selective electrochemical fluorination of organic compounds in ionic liquids. J Fluorine Chem 2005 126: $181-7$

[9] Mootz D, Poll W, Boenigk D, Bartmann K. Hydrogen-fluoride crystal-chemistry. Abstracts of papers of the American Chemical Society 1992; 203: 44.

[10] Boenigk D, Mootz D. The system pyridine hydrogen-fluoride at low-temperatures - formation and crystal-structures of solid complexes with very strong NHF and FHF hydrogen-bonding. J Am Chem Soc 1988; 110: 2135-9.

[11] Gennick I, Harmon KM, Potvin MM. Preparation properties and low-temperature infrared structural analysis of ammonium and alkylammonium trihydrogen tetrafluorides and tetramethylammonium dihydrogen trifluoride. Inorg Chem 1977; 16: 2033-40.

[12] Whittlesey MK, Perutz RN, Greener B, Moore MH. Synthesis, molecular structure and NMR spectroscopy of a transition-metal bifluoride complex: formation via $\mathrm{C}-\mathrm{F}$ activation or reaction with $\mathrm{Et}_{3}$ N.3HF. Chem Commun 1997; 2: 187-8.

[13] Wagner G, Pardi A, Wuethrich K. Hydrogen bond length and proton NMR chemical shifts in proteins. J Am Chem Soc 1983; 105: 5948-9.

[14] Zhao Q, Abeygunawardana C, Gittis AG, Mildvan AS. Hydrogen bonding at the active site of $\Delta^{5}$-3-Ketosteroid isomerase. Biochemistry 1997; 36: 14616-26. 
[15] Sharp R, Lohr L, Miller J. Paramagnetic NMR relaxation enhancement; recent advances in theory. Prog Nucl Magn Reson Spectrosc 2001; 38: 115-58.

[16] Gaggelli E, Amelio ND, Valensin D, Valensin G. ${ }^{1} \mathrm{H}$ NMR studies of copper binding by histidine-containing peptides. Magn Reson Chem 2003; 41: 877-83.
[17]

Purcell EM, Pound RV, Bloembergen N. Nuclear magnetic resonance absorption in Hydrogel gas. Phys Rev 1946; 70: 986-7.

[18] Practical NMR Relaxation for Chemists. Practical 1 NMR Relaxation for chemists Vladimit I. Bakhmutov. John wiley and Sons 2004; pp. 42-5.

Received: July 10, 2011

Revised: September 20, 2011

Accepted: September 21, 2011

(c) Ilayaraja et al.; Licensee Bentham Open.

This is an open access article licensed under the terms of the Creative Commons Attribution Non-Commercial License (http://creativecommons.org/licenses/ by-nc/3.0/) which permits unrestricted, non-commercial use, distribution and reproduction in any medium, provided the work is properly cited. 